\title{
Disability and work intensity in Italian households
}

\author{
Elena Calegari ${ }^{1} \cdot$ Enrico Fabrizi $^{1} \cdot$ Chiara Mussida $^{1}$
}

Received: 8 May 2020 / Accepted: 12 March 2021 / Published online: 1 April 2021

(c) The Author(s) 2021

\begin{abstract}
The 2030 Agenda of the United Nations clearly sets the inclusion of persons with disabilities in the labour market as a main goal. However, especially in care welfare systems characterized by a low level of social services, disability not only impacts the labour market participation of disabled people themselves but may also affect the labour opportunities of other members of their household. Using EU-SILC data to compute individual work intensity-as a better measure of the actual level of labour attainment-this paper aims to disentangle direct and indirect correlations between disability and labour market participation in Italian households. In confirming the negative direct correlation between disability and labour market participation, the results also show a negative indirect correlation that depends on the family relationship between the disabled person and household members.
\end{abstract}

Keywords Disability · Care Regimes · Work Intensity · Italian Households · Ordered Logit

JEL classification $\mathrm{J} 14 \cdot \mathrm{J} 15 \cdot \mathrm{J} 21 \cdot \mathrm{C} 25 \cdot \mathrm{D} 10$

\section{Introduction}

In setting its sustainable development goals, the United Nations 2030 Agenda devotes special attention to social inclusion, and more specifically, to the labour market participation of weak categories of workers (United Nations, 2019). Among these, disabled persons receive special consideration, with the exhortation to remove the physical barriers to participation and to implement active policies for their actual inclusion in the job market (United Nations, 2018). This document is line with previous documents of the same type from the European Union's 2020 Agenda

Elena Calegari

elena.calegari@unicatt.it

1 Department of Economic and Social Sciences, Universitá Cattolica del Sacro Cuore, Piacenza, Italy 
(European Commission, 2010), testifying to a long-standing problem and significant challenge in the path to the creation of inclusive societies.

The existing literature focuses primarily on the so-called direct correlation, that is, the correlation between disability and the labour market participation of the disabled person (Agovino et al., 2014; Gannon, 2005; García-Gómez et al., 2010; Oguzoglu, 2010). Despite mixed empirical findings about the direction of the effect, the majority of the evidence points to a negative correlation, showing that physical limitations reduce the labour market participation of disabled persons.

However, an individual's disability not only correlates with the work opportunities of the disabled person but also with the job market participation of other household members (Nys et al., 2016); this is labelled as the indirect correlation, or cross-correlation, of disability. This indirect correlation can either be positive or negative. On the one hand, by inducing extra costs related to care (Cullinan et al., 2011; Mitra et al., 2017; Morciano et al., 2015; Morris \& Zaidi, 2020), the presence of the disabled person may lead some members of the household to work more in order to sustain the higher level of expenses (Eichhorst et al., 2010). On the other hand, the presence of the disabled person might lead some other members to dedicate less time to their jobs because of the need for extra time to take care of him/her. In particular, this negative indirect correlation may be more severe in countries (social contexts) in which care regimes are characterized by a limited development of social services and a strong informal care system, as was traditionally the case in Italy (Da Roit \& Sabatinelli, 2013). Indeed, in the absence of an adequate provision of services for persons with disabilities, care duties may be left to specific members of the household, depending on the family relationship between the disabled person and the worker or on gender (Atkinson et al., 2007; Parodi \& Sciulli, 2008; Vinck \& Van Lancker, 2020; Wasi et al., 2012).

Since the latest economic recession, the labour market has been characterized by increasing flexibility, implying a strong instability of working conditions and reduced working hours. It is debated whether the presence of a disabled person can be described only by the participation/non-participation of some components of the household in the labour market or whether it is more meaningful to consider the amount of time spent at work and the stability of employment (Brandolini \& Viviano, 2016; Lilly et al., 2010; Nys et al., 2016).

In order to better capture the correlation between disability and labour market participation, it is possible to use work intensity, an indicator adopted by Eurostat (Ayllón \& Gábos, 2017; Meulders, 2013). Work intensity is calculated at the household level as "the number of months that all working age household members have been working during the income reference year as a proportion of the total number of months that could theoretically be worked within the household"; ${ }^{1}$ Work intensity can also be calculated at the individual level. Individual work intensity, especially in contexts of flexible labour markets, can provide a more reliable measure of labour market involvement with respect to one's labour market status and allows disentangling participation effects of disability that would otherwise remain hidden.

\footnotetext{
${ }^{1}$ For a detailed explanation, see the Eurostat website: https://ec.europa.eu/eurostat/statistics-explained/ index.php/EU_statistics_on_income_and_living_conditions_(EU-SILC)_methodology_-_definition_of_ dimensions\#Work_intensity_of_the_household.
} 
In this perspective, this paper contributes to the existing literature on the labour market effects of disability in two different dimensions. First, by using individual work intensity, it offers novel evidence on the correlation between the presence of a disabled person in a household and individual labour participation. Second, the paper focuses on both direct and indirect correlations of disability with the labour market participation of household members (Mussida \& Sciulli, 2016). On the one hand, we estimate the correlation between disability and the individual work intensity of a disabled person, considering his/her degree of disability, and on the other hand we also estimate the correlation between the presence of the disabled person and the individual work intensity of household members, distinguishing between different family relationships that can hold between the disabled person and household members.

Our analysis is based on a sample of Italian households with at least one member of working age (18-59 years old). Because of the relevance of care regimes in shaping labour market participation in the presence of disabled persons in the household (Simonazzi, 2009), Italy represents an interesting case study. On the one hand, the Italian welfare system is characterized by a low level of care-service supply (Bettio \& Plantenga, 2004; Da Roit et al., 2013) that is often replaced by strong informal care provision (Da Roit \& Sabatinelli, 2013; Le Bihan et al., 2019), thus giving room to the possible reduction of labour market attainment for the members of the household appointed to this care. On the other hand, in Italy the scarcity of public care services is counterbalanced by a cash allowance scheme for elderly and disabled individuals (Ranci Ortigosa et al., 2008) that supports the provision of other types of private care services, frequently undertaken by migrant caregivers (Bettio et al., 2006; Da Roit et al., 2013), thus unburdening the other members of the household (especially women) of care duties. The results estimated for the Italian case can be extended to other countries with similar care welfare systems, such as the other Southern European countries (Bettio \& Plantenga, 2004).

Specifically, we consider data from the 2016 wave of the EU Statistics on income and Living Conditions (EU-SILC) survey. In this survey, the only information about disability is a self-reported disability assessment that distinguishes three levels: no disability, mild and severe disability. ${ }^{2}$

A preliminary comparison between households with and without disabled members suggests that in households with at least one disabled person, the average work intensity of the other household members is significantly lower.

After discretizing individual work intensity into four (increasing) levels, we use an ordered logit model to evaluate the direct and indirect correlations of disability, along with a wide set of covariates that can also be associated with work intensity and thereby act as confounding factors (Gannon, 2005).

Results show that disability has a direct negative correlation with the work intensity of the disabled person, but this negative correlation is statistically significant only if the disability is severe. Moreover, the presence of a severely disabled person in the household has a negative indirect correlation with the work intensity of the other household members, reducing their work intensity. This correlation related to the presence of a disabled person changes according to the family relationship that

\footnotetext{
$\overline{2}$ For an extensive discussion of the use of self-reported disability see Section 2.2.
} 
holds between the disabled person and the cohabiting household member, indicating the importance of distinguishing between different family relationships. The paper proceeds as follows. Section 2 discusses the measure of work intensity and the issues related to the use of self-reported disability data. Section 3 describes the estimation methodology, and Section 4 presents the data included in the estimated empirical model and the main descriptives. Section 5 discusses the results, and Section 6 concludes and offers some policy implications.

\section{Measurement issues}

\subsection{The work intensity indicator}

Most studies of labour market participation rely on the categorical labour market statuses that are used in the calculation of employment and unemployment rates (ILO, 2019), which represent the most common indicators to describe labour market dynamics (Kidd et al., 2000). Brandolini \& Viviano (2016) hhighlight that these rates offer only a partial view of the labour market, especially in contexts characterized by high flexibility, like the Italian one. Indeed, data show that in recent years the growth of the employment rate has not been followed by a proportional increase in worked hours, unveiling that the number of individuals who have a job offers different information with respect to how much they work. For instance, in labour markets characterized by a significant use of fixed-term contracts, it is possible that workers hired for fixed terms work less with respect to people hired on a permanent basis, especially if they have a part-time job.

Assessing how much people work is especially relevant in studies of the correlation between disability and labour market participation. Looking both at the direct and indirect correlation between disability and labour market participation, physical limitations may be relevant not only to the decision regarding whether to participate or not in the labour market but also to the decision about how much time to dedicate to the job. In particular, regarding the indirect correlation, in households with a disabled person it is possible, on the one hand, that members of the household decide to work more in order to afford the extra costs related to disability (Cullinan et al., 2011; Morciano et al., 2015; Morris \& Zaidi, 2020) or, on the other hand, some members who participate in the labour market may renounce some working hours to dedicate themselves to care responsibilities.

To better disentangle these correlations, we propose using a more flexible measure of labour market participation. Specifically, we consider the work intensity indicator defined above, which was introduced by Eurostat for all working-age household members. Working-age persons are defined as individuals aged between 18 and 59 but excluding dependent children. ${ }^{3}$

Note that work intensity originally defined at the household level for the computation of social exclusion indicators in the framework of the European Union's

\footnotetext{
3 For a detailed explanation, see the Eurostat website: https://ec.europa.eu/eurostat/statistics-explained/ index.php/EU_statistics_on_income_and_living_conditions_(EU-SILC)_methodology_-_definition_of_ dimensions\#Work_intensity_of_the_household.
} 
2020 Agenda (Ayllón \& Gábos, 2017; European Commission, 2010, 2014) can be computed also at the individual level. This individual-level definition has several advantages. It is a continuous measure ranging from 0 to 1 , allowing for a richer picture of labour market participation, and it is computed separately for each household member of working age, allowing for the measurement of both direct and indirect correlations of disability.

An intermediate individual working intensity (i.e. not 0 or 1) may reflect a decision to work for only part of the year or a weaker position in the labour market that is more liable to the acceptance of fixed-term contracts.

We note that work intensity as defined above has some limitations, however. It is focused on the months worked rather than on the hours worked. Furthermore, although it can take any value between 0 and 1, in the majority of cases it is equal to 0 or 1 , with intermediate values peaking around 0.5 or other typical approximations related to the response process. It is then more convenient to group work intensity values into categories. In this study, we follow the EU-SILC survey, which offers four categories of work intensity (variable HX020 in the EU-SILC questionnaire): $0,(0,0.5),(0.5,1)$, and 1 . Moreover, we extend the Eurostat definition of work intensity to account for part-time employment. Specifically, months worked part-time are downweighted when computing the total months worked. Downweighting is based on assuming that part-time employment counts for $52.5 \%$ of full-time employment. ${ }^{4}$ Part-time employment may reflect either a decision by the individual regarding his/her time allocation (especially when living with or taking care of a disabled person) or a forced decision due to a weaker position on the labour market.

\subsection{The assessment of disability}

In the present paper, we use as a measure of disability the self-reported physical limitation status reported in item PH030 of the EU-SILC questionnaire (for details, see Section 4.2). Respondents are all household members aged 16 and over, and they are asked to ascribe a categorical status to the "Limitation in activities because of health problems" condition. General activity limitations are defined as limitations in conducting normal activities as a result of health problems, for at least six months before the interview. The respondents can choose among three alternatives: "Yes, strongly limited", "Yes, limited" or "No, not limited". The evaluation is therefore subjective and without any reference to the age of the individual or anchoring to an average condition (as occurs in other surveys (see, for instance, Contoyannis, Jones and Rice (2004)).

The reliability of subjective measures of disability is widely debated in the literature, with some authors backing the reliability of these assessments (Burkhauser et al., 2001; Stern, 1989) and others claiming their inaccuracy (Gannon, 2005).

\footnotetext{
${ }^{4}$ Given that the Italian legislation for full- and part-time jobs (Legislative Decree No 66/2003 and the more recent Legislative Decree No 81/2015, the Jobs Act) does not specify the precise amount of hours worked by part-timers, we use the data provided by the Italian National Institute of Statistics (ISTAT) to obtain a coefficient to use for part-time workers. We calculate the ratio between working hours of parttimers and working hours of full-timers. We obtain a coefficient of 0.525 , which we use to weight the work intensity of part-time workers in our sample.
} 
Others highlight that there may be a specific measurement error, called "response category cut-point shift" (Murray et al., 2001; Sadana et al., 2002), that occurs because some subgroups of the population may systematically over-report their disability status because of different cut-point levels in the perceptions of their physical limitations (Contoyannis et al., 2004). Moreover, the over-reporting of disability conditions in self-reported data may also be due to the fact that some work categories tend to use disability to justify their working status (Bound \& Burkhauser, 1999)-mostly in the case of unemployed individuals-creating a relationship between the self-reported physical status and the labour market outcome (Agovino et al., 2014). However, despite these issues regarding self-reporting, in a comparison of different countries Burkhauser, Daly, McVicar and Wilkins (2014) showed that the proportion of individuals assessing themselves as disabled is almost constant over time in each country, thus reducing the seriousness of the issue for single-country studies.

\section{Model}

The target variable we consider in our analysis is individual work intensity. We aim to assess the correlation between work intensity and an individual's disability or that of other household members, along with many other covariates described in Section 4.2. As individual work intensity levels have been grouped into four categories endowed with a natural increasing order, we consider an ordered logit regression in our analysis.

Let $i$ be the index for the individuals in the sample $(i=1, \ldots, n)$ and $y_{i}$ the ordinal dependent variable we are modelling, such that $y_{i}$ can take values in the set $C=\{1$, $2,3,4\}$. The key assumption in the ordered logit model is that

$$
P\left(y_{i} \leq k\right)=\frac{\exp \left(\alpha_{k}+\mathbf{x}_{i} \boldsymbol{\beta}\right)}{1+\left[\exp \left(\alpha_{k}+\mathbf{x}_{i} \boldsymbol{\beta}\right)\right]}
$$

$k=1,2,3$ and $\mathbf{x}_{i}$ is a vector of regressors associated to unit $i ; \alpha_{k}$, and $\beta$ are unknown parameters. Specifically, $\alpha_{k}, k=1,2,3$ are known as "cut-off points" (Greene, 2003), while $\beta$ are the assumed common slopes. The category-specific intercepts are constrained such that $\alpha_{k}<\alpha_{k+1}, k=1,2$.

To facilitate the interpretation of the results, the estimated coefficients of the ordered logit model are reported as odds ratios.

\section{Data and summary statistics}

\subsection{Data}

We analyse data from the 2016 EU-SILC survey for the Italian sample. The survey is conducted in most countries across the European Union by the relevant national institutes of statistics using harmonized questionnaires and survey methodologies. Although they follow common guidelines, sampling designs can differ from country to country. In Italy, the EU-SILC is a rotating panel survey with $75 \%$ overlap of samples in successive years. 
The fresh part of the sample is drawn according to a stratified two-stage sample design where municipalities (LAU 2 level) are the primary sampling units (PSUs) and households are the secondary sampling units (SSUs). The PSUs are divided into strata according to their population size, and the SSUs are selected by systematic sampling in each PSU. Our analysis considers the cross-sectional sample of households interviewed in 2016.

We focus on households with at least one member of working age (18-59 years old) and at least one disabled member (with either mild or severe disability). For comparison purposes, households with at least one person of working age but no disabled members are also considered. The statistical units in our models are individuals aged between 18 and 59 who are not dependent children and for whom work intensity is computed according to Eurostat guidelines. ${ }^{5}$ A dependent child is a person between 18 and 24 years old who lives with at least one parent and is not economically active.

\subsection{The determinants of the individual work intensity}

Table A1 reports descriptive statistics for the variables used in our analyses for the samples of households with and without disabled members. The dependent variable of the estimated model on the sample of main interest, that is, households with disabled members, is the individual work intensity categorized into four levels, as discussed in Section 2.1. We note that $36 \%$ of the sample has an individual work intensity equal to 0 , for $49 \%$ the work intensity equals 1 , only $3.2 \%$ falls in the range of $0-0.5$, and the remaining $12 \%$ falls in the range of $0.5-1$.

The explanatory variables of primary interest aim to capture both direct and indirect correlations of disability. For direct correlations, we include two dichotomous variables (Own Mild Disability and Own Strong Disability) to account for the degree of individual disability (Gannon, 2005; Mussida \& Sciulli, 2016). As expected, Table A1 and Figure 1 show that the number of disabled persons, as well as the degree of disability, are positively associated with the age of the individual.

For indirect correlations, which involve the investigation of whether the presence of a disabled person in the household correlates with the work intensity of other household members (Nys et al., 2016; Parodi \& Sciulli, 2008), we include a dummy variable for the presence of a disabled household member with a severe disability. Furthermore, given that these (indirect) correlations might be different according to the family relationship that occurs between the disabled person and the worker (Lilly et al., 2010), we include three dummy variables for familiar relationship: Parent (Atkinson et al., 2007; Vinck \& Van Lancker, 2020; Wasi et al., 2012), Son/ Daughter (Luppi \& Nazio, 2019; Schneider et al., 2013), and Partner (Parodi \& Sciulli, 2008). The EU-SILC survey reports infor mation regarding physical limitations of household members from 16 years of age onwards, thus underrepresenting the number of children with disabilities in households. This may

\footnotetext{
5 More information about EU-SILC can be found here: https://ec.europa.eu/eurostat/statistics-explained/ index.php?title=EU_statistics_on_income_and_living_conditions_(EU-SILC)_methodology_\%E2\%80\% 93_concepts_and_contents.
} 


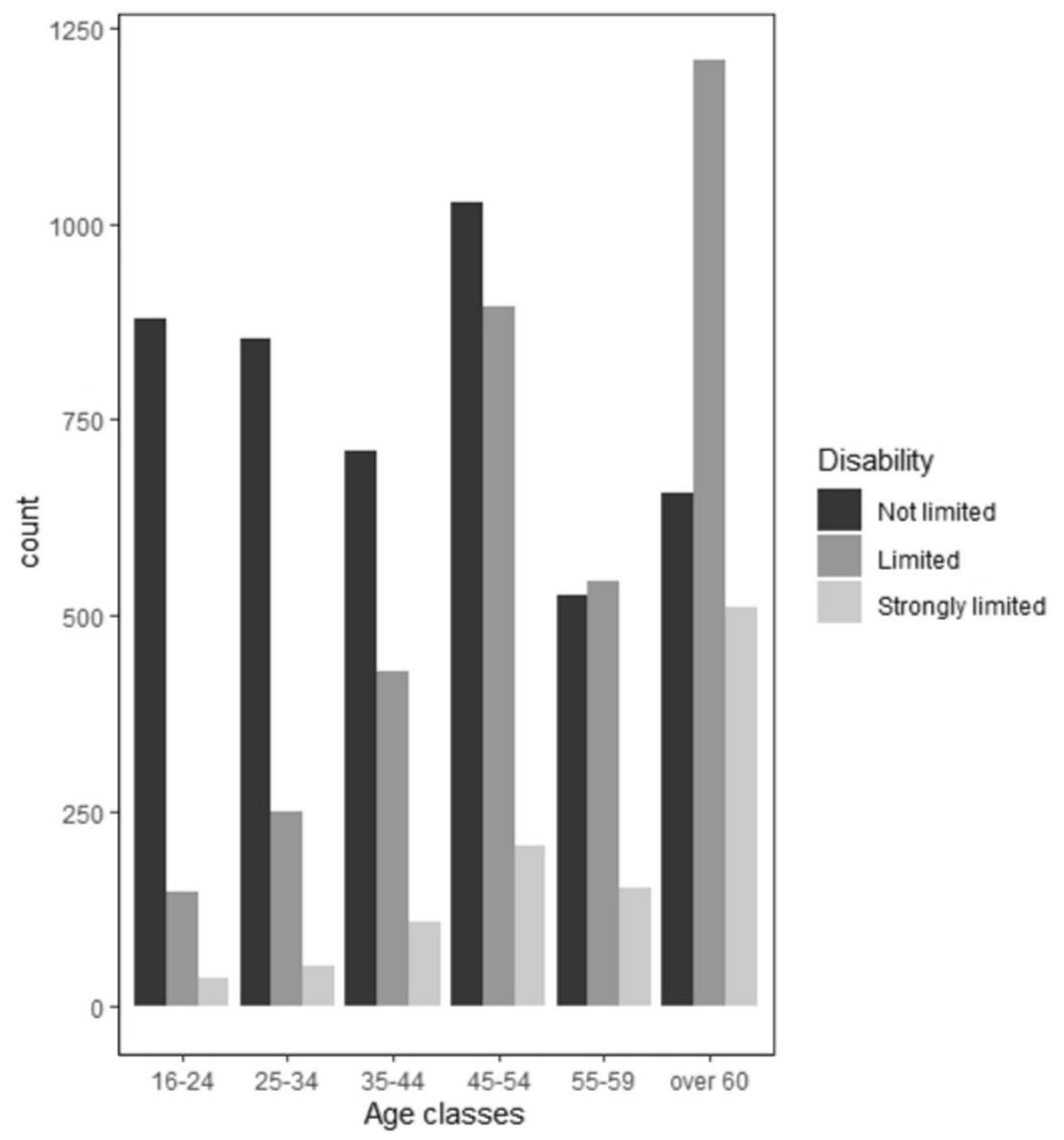

Fig. 1 Number of individuals by age class and degree of disability

partially explain the relatively small percentage of parents of disabled persons (7\%). We will offer a robustness check for this (see Section 5 and Table A2).

The model takes into account the widely recognized gender differences in labour market attainment (Agovino et al., 2014; Antecol, 2000; Garcia-Gomez et al., 2010; Parodi \& Sciulli, 2008), both by means of the dummy variable Female and by including the interaction between that variable and the presence of a severe disabled person in the household.

We control for age and educational attainment level because, as suggested by the literature, these might influence individual work intensity (Cai, 2010; Gannon, 2005; Oguzoglu, 2010). Age is categorized into five classes in order to allow for possible non-linear effects. To account for the association that may hold between the presence of young children in the household and the work intensity of adult members (Cai, 2010; Gannon, 2005; Mussida \& Sciulli, 2016), the model includes a dummy variable for the presence of at least one child between 0 and 15 years of age. 
We also include the interaction between Female and Kids to capture possible differences in labour supply for females with children and labour supply for men with children.

As income level might be associated with labour market participation (Mussida \& Sciulli, 2016), it is possible that the work intensity of one member of the household may be affected by the incomes of other members. For each individual in a household, we compute the Other Members Income variable, given by the sum of the incomes of all members of the household other than the considered individual. In the model, we include indicators for the quartiles of this variable, allowing for possible non-linear effects.

Moreover, a dummy variable for non-Italian-born individuals is included in the model to account for the fact that the presence of a disabled household member may show a different correlation for immigrants with respect to natives (Oguzoglu, 2010).

The socio-economic environment may be associated with individual work intensity (Mussida \& Sciulli, 2016). Given that in Italy, differences in the socio-economic environment may be well described by geographical discrepancies, the model includes dummies for the geographical area of residence (North, Centre, South) (Garcia-Gomez et al., 2010; Parodi \& Sciulli, 2008), as well as a variable to distinguish between individuals living in urban or rural areas (Oguzoglu, 2010).

We also control for the presence of at least one elderly non-disabled person in the household, defined as a person older than 65 years old who does not show physical limitations. Indeed, being income recipients with only limited care needs, they may influence the labour market participation of the working-age household members. We also control for household size (N components) and home ownership (Owner).

As shown in Table A1, in the sample of households with at least one disabled member the explanatory variables show similar averages and shares with respect to the sample of households without a disabled member. This evidence may suggest that there are no specificities in the main characteristics of the two groups. However, if we look at the individual work intensity, we find that the average work intensity of individuals living in households with a disabled member is statistically lower with respect to the average in households without disabled members ( $p$ value $\simeq 0$ ), giving justification for the model estimated in Section 5.

Finally, we are aware of the existence of at least two aspects of the Italian institutional context that need to be reported for their possible correlation with the work intensity of both disabled persons and their (non-disabled) household members. The first is the obligation for Italian firms with more than 14 employees to hire disabled workers, stemming from Law No 68/1999. This law imposes on firms the requirement of hiring an increasing number of disabled workers as the number of employees increases. It is likely that disabled workers employed in large firms are benefiting from this law and therefore work all year. The second issue is related to the effects of Law No 104/1992, which gives up to three days per month of paid leave to workers with children or close relatives with a disability or serious illnesses. This leave does not apply to self-employed workers or to workers in the informal sector. Moreover, working in the public sector or in large firms probably offers more guarantees with respect to the granting of rights offered by 
the law. In our data, we have information on the sector of economic activity of firms, and we build a proxy for working in the public sector. ${ }^{6}$ Unfortunately, there is no information on the firm size, but we are aware of its possible positive correlation with work intensity.

\section{Results}

Table 1 reports the odds ratios from the estimated ordered logit models. We are aware of the fact that by using only one cross-sectional dataset (for 2016) we cannot interpret our results as causal effects of being a disabled person on work intensity, as issues related to reverse causality and/or unobserved factors cannot be ruled out. Our results must therefore be interpreted as correlations. In column (1) of Table 1, we report the results for the whole sample. In columns (2) and (3), we report the estimates for the subsamples of households with at least one disabled member and those without, and in column (4) we test for equality of the coefficients for the two subsamples (see the Appendix for details).

The estimates on the whole sample are reported as a supplementary analysis. We note that the odds ratio for the determinants of work intensity are similar to those estimated for the subsample of households with at least one disabled household member. This reassures us about the robustness of our results.

Looking in detail at the estimated odds ratios of main interest (column (2)), we first note the negative association between disability and labour market participation (Agovino et al., 2014; Cai, 2010; Gannon, 2005; Kidd et al., 2000; Mussida \& Sciulli, 2016; Oguzoglu, 2010).Interestingly, we note that severe disability leads to a statistically significant reduction of work intensity, whereas mild limitations have no significant correlation.

As for the indirect correlation of disability, the presence of a severely disabled household member has an overall negative correlation with the work intensity of the other members of the household (Nys et al., 2016; Parodi \& Sciulli, 2008); but interestingly, we find that the correlation is diversified according to the family relationship each member has with the disabled person. Specifically, while being the son/daughter of a disabled individual does not affect work intensity, being a parent or partner moderates the overall negative correlation with work intensity.

For parents, the moderation may be due to the fact that for young persons with disabilities there are several options for care, both formal (such as the public education system and volunteer centres) and informal (such as grandparents who can take care of them (Zanobini et al., 2018), allowing the parents to work more to afford the extra costs related to the disability (Cullinan et al., 2011; Morris \& Zaidi, 2020). For partners, a likely cause is the need to balance the loss of income that might occur in case of disability if not adequately compensated by the public cash allowance received, as is likely to be the case for Italy (Ranci et al., 2008).

\footnotetext{
${ }^{6}$ From the variable PL111 in the EU-SILC code, we build a dummy variable equal to one if the sector is public administration and defence, compulsory social security, education or health and social work, and 0 otherwise.
} 
Table 1 Ordered logit model odds ratios estimated for the whole sample and for the two separate subsamples, and $\mathrm{T}$ statistics for the comparison between estimated coefficients

Dependent variable: Class of Work Intensity

(1) (2) (3)

(4)

Whole Sample Households with Households T statistics without

Disabled member (s) Disabled

member (s)

Age - reference: age 35-44

\begin{tabular}{|c|c|c|c|c|}
\hline Age 18-24 & $0.216^{* * *}$ & $0.252^{* * *}$ & $0.210^{* * *}$ & $1.71^{*}$ \\
\hline Age $25-34$ & $0.494^{* * *}$ & $0.504^{* * *}$ & $0.495^{* * *}$ & 0.241 \\
\hline Age $45-54$ & $1.223^{* * *}$ & $1.135^{*}$ & $1.243^{* * *}$ & -1.411 \\
\hline Age 55-59 & 1.049 & 0.929 & 1.084 & $-2.140^{* *}$ \\
\hline
\end{tabular}

Edulevel - reference: primary

Edulevel (secondary)

$2.109^{* * * *}$

$2.169^{* * *}$

$2.083^{* * *}$

0.851

Edulevel (tertiary)

$3.032^{* * * *}$

$2.943^{* * * *}$

$3.073^{* * *}$

$-0.634$

Female

$0.370^{* * *}$

$0.346^{* * *}$

$0.352^{* * *}$

0.263

Kids

$2.474^{* * *}$

$1.729^{* *}$

$2.690^{* * *}$

$-4.800^{* * * *}$

Female* kids

$0.337^{\text {*** }}$

$0.527^{* * *}$

$0.305^{* * *}$

$5.188^{* * *}$

Immigrant

$0.694^{* * *}$

$0.724^{* * *}$

$0.674^{* * *}$

0.888

Other members income -

reference: $3 q$

Other members income $1 \mathrm{q}$

$1.389^{* * *}$

$1.412^{* * *}$

$1.340^{* * * *}$

$-0.849$

Other members income $2 q$

$1.148^{* * *}$

$1.309^{* * *}$

$1.097^{* * * *}$

$2.911^{* * *}$

Other members income $4 \mathrm{q}$

$0.930^{*}$

1.064

$0.882^{* * *}$

$2.998^{* * *}$

Own strong disability

$0.293^{* *}$

$0.494^{* * *}$

Own mild disability

$0.739^{* * *}$

0.949

Presence of severe disabled

$0.733^{* * *}$

$0.623^{* * *}$

$N$ components

$0.873^{* * *}$

1.014

$0.722^{* * *}$

0.892

$0.828^{* * *}$

$8.679^{* * *}$

Elderly nd

Region - reference: center

$$
\text { Region (north) }
$$

$1.208^{* * *}$

$1.377^{* * *}$

$0.683^{* * *}$

$3.321^{\text {*** }}$

Region (south)

$0.478^{* * *}$

$0.503^{* * *}$

$1.138^{* * *}$

$3.723^{* * * *}$

Urban

$1.119^{* * *}$

$1.132^{* * *}$

$0.683^{* * *}$

1.478

Owner

$1.131^{* * *}$

1.007

$1.112^{* * *}$

0.643

Public employee

$2.255^{* * *}$

$2.899^{* * *}$

$1.161^{* * * *}$

$-3.166^{\text {*** }}$

Parent

$1.332^{* *}$

Son/daughter

0.962

Partner

$1.190^{* *}$

Female* presence of severe

$1.635^{* * *}$

disabled

Observations

23715

6039

17676

AIC

42889.64

11728.15

31046.45

${ }^{*} p<0.1 ;{ }^{* *} p<0.05 ;{ }^{* * *} p<0.01$ 
Our estimates confirms the gender differential in labour market participation between men and women (Antecol, 2000), and more specifically the disadvantage of women, who work less than men in both households with and without disabled members. Nonetheless, our estimates show that this correlation is moderated by the presence of a disabled person, especially if they are strongly physically limited (as suggested by the interaction term). An explanation for this may be related to the presence of private caregivers in the households, which allows women-who are traditionally designated to perform informal care (Cordini \& Ranci, 2017; Da Roit \& Sabatinelli, 2013)-to increase the amount of paid work they do in order to afford the extra costs related to disability.

Looking at the other covariates, the estimates offer further interesting insights. First, differently from previous research (Bernardi et al., 2011), our results suggest that both in households with (column (2)) and without disabled members (column (3)), immigrants tend to have a lower work intensity with respect to natives. Second, the results confirm the Italian territorial dualism between North and South, with the South showing a structurally lower work intensity with respect to the North. Nonetheless, the presence of a disabled person in the household seems to widen the distance between the North and Centre regions of the country, which sees their advantage with respect to the South reduced.

The variables describing the correlations between the income of the other members of the household and the individual work intensity exhibit the expected sign, meaning the lower the income of other household members, the stronger is the need to work. If we compare households with and without disabled members, the impacts are not significantly different for the first quartile (with respect to the third used as reference category) but are higher for households with a disabled member in the second, in line with the higher expenses these households face. A high income (fourth quartile) for other household members is significantly and negatively associated with work intensity only in households with a disabled member.

Consistently, the presence of an elderly non-disabled person-who is likely to receive an old-age pension-reduces the individual work intensity in households without disabled members. For elderly care, as also confirmed by the literature (see, for instance, Theobald \& Luppi (2018)), Italy appears to score rather favourably compared to other European countries with respect to the adequacy of financial resources, namely of state support provided through public pension schemes for the elderly. The presence of an elderly person does not correlate with work intensity in households with disabled members. These two results show how in the presence of a disabled person, none of the potential incentives for a reduction of work intensity (such as a high income for the other members of the household or an elderly nondisabled person who can help both economically and practically) are effective, confirming that the members of these households are forced to work to afford the extra costs associated with the presence of a disabled person.

Moreover, the estimates show that individual work intensity is positively associated with the presence of children between 0 and 15 years of age, even though the correlation is different for men and women (the interaction between Female and the presence of children shows a disadvantage for the labour supply of females with respect to that of males). What emerges is that in households with a disabled person, the female labour supply is more negatively affected by the presence of children than 
in households without a disabled person. This result suggests that men increase the amount of months worked in order to afford the higher expenses related to children but that the presence of a disabled person represents a limitation to this arrangement.

With respect to age, the results show that young workers have a lower work intensity with respect those aged between 35 and 44 years of age, pointing to difficulties for young workers in finding full-time jobs in a flexible labour market like the Italian one. The correlation between age and working intensity does not differ very much between households with and without disabled members. Level of education is positively associated with work intensity, in line with previous literature (Gannon, 2005; Lilly et al., 2010; Oguzoglu, 2010). Also in line with expectations, having a job in the public sector is positively correlated with a higher work intensity.

Finally, we offer both a robustness check and a supplementary set of estimates, which are reported in Tables A2 and A3 in the Appendix. First, given that-as explained in Section 4.2-the EU-SILC survey offers information on disability only for individuals older than 16, we run the estimates on the sample of households in which there are no children under 16 years of age. The odds ratio are reported in Table A2. We note that the estimates are similar to the main model. Second, as it may be argued that the cash disability benefits may be a determinant of individual work intensity, we estimate our main model by including a dichotomous variable for individuals who receive disability cash benefits (Table A3). We see that most of the odds ratio remain more or less the same; the inclusion of disability benefits increases the the magnitude of the odds ratio Own Strong Disability. This might be due to the fact that disability benefits in the Italian welfare system, known as indennitá di accompagnamento (for details, see Ranci et al. (2008)), are cash allowance provided almost solely for totally or very strong disabled individuals.

\section{Conclusions and policy implications}

As underscored in the UN's 2030 Agenda, which recalls the previous EU 2020 Agenda, labour force participation is an important factor for the promotion of social inclusion. Households with disabled members experience a greater risk of social exclusion compared to households without disabled members. This is partially due to the role of labour force participation in the computation of the social exclusion indicator.

Disability, especially in care welfare systems characterised by a low provision of social services, affects labour market participation and the employment of disabled persons themselves, and it may affect the labour market opportunities of their respective household members.

While the existing literature primarily focuses on the direct correlation between disability and employment or labour market participation, we offer novel evidence of both direct and indirect correlations of disability by distinguishing the family relationships between a disabled person and other household members, as well as by adopting individual work intensity as a measure of labour market participation.

We use EU-SILC data to estimate an ordered logit model for the correlation between disability and individual work intensity for a sample of Italian households. In Italy, consistent with care-regime theory, it appears that prevailing mechanisms 
relegate women to the role of informal caregiver, most likely because of inadequate formal disability-care services.

In confirming the negative direct correlation of disability, our results also show an indirect negative correlation that, interestingly, depends on the family relationship that holds between the disabled person and other household members. While being a son/daughter of the disabled person does not correlate with work intensity, being a parent or partner moderates the negative indirect correlation.

Our findings offer interesting policy implications at least in two dimensions. First, to mitigate the negative direct correlation between disability and work intensity, it would be opportune to implement measures to increase the social inclusion of disabled persons and, more specifically, their labour market participation. Such measures include the improvement of available infrastructure, including the transport system, and the adaptation of workspaces. Second, to additionally mitigate the negative indirect correlation, some mechanisms are needed to induce an increase in the labour supply of parents and partners, possibly to cover the extra costs associated with disability. This pattern would be compatible with the increasing presence of institutions, including disability daycare centres, volunteer centres, and family and employment policies (including part-time) that better reconcile unpaid and paid work roles, especially for women. Additionally, and more in general, housing policies supporting housing costs may relieve households facing the extra costs of disability and thus free up resources to finance formal disability care.

Finally, our supplementary analyses suggest that the existing cash allowances for totally or severely disabled persons are likely inadequate as these do not have a significant effect on the work intensity of either disabled persons themselves or their relatives.

Funding Open access funding provided by Universitá Cattolica del Sacro Cuore within the CRUICARE Agreement.

\section{Compliance with ethical standards}

Conflict of interest The authors declare no competing interests.

Publisher's note Springer Nature remains neutral with regard to jurisdictional claims in published maps and institutional affiliations.

Open Access This article is licensed under a Creative Commons Attribution 4.0 International License, which permits use, sharing, adaptation, distribution and reproduction in any medium or format, as long as you give appropriate credit to the original author(s) and the source, provide a link to the Creative Commons license, and indicate if changes were made. The images or other third party material in this article are included in the article's Creative Commons license, unless indicated otherwise in a credit line to the material. If material is not included in the article's Creative Commons license and your intended use is not permitted by statutory regulation or exceeds the permitted use, you will need to obtain permission directly from the copyright holder. To view a copy of this license, visit http://creativecommons.org/licenses/by/4.0/.

\section{Appendix}

Table A1 


\subsection{Test for the quality of the coefficients between estimated models}

To check for possible structural differences in the determinants of individual work intensity in households with disabled members with respect to households without disabled members, we test for the difference between the coefficients of the two models estimated in columns (2) and (3) of Table 1. Column (4) reports the value and the significance of the following test statistic (Cohen et al., 2003):

$$
T=\frac{b_{1}-b_{2}}{\sqrt{s e\left(b_{1}\right)^{2}-s e\left(b_{2}\right)^{2}}}
$$

given $\boldsymbol{X}_{\mathbf{1}}$ the design matrix of Model in column (2) of Table $1, b_{1}$ is the coefficient belonging to $\boldsymbol{X}_{\mathbf{1}}$ and, given $\boldsymbol{X}_{\mathbf{2}}$ the design matrix of Model in column (3) of Table 1, $b_{2}$ is the coefficient belonging to $X_{2}$. $s e\left(b_{1}\right)$ and $s e\left(b_{2}\right)$ are the standard errors of the coefficients.

Table A2 and Table A3

Table A1 Variables Included in the estimated model (Source: EU-SILC 2016)

\begin{tabular}{|c|c|c|c|}
\hline \multirow[t]{2}{*}{ Variable } & \multirow[t]{2}{*}{ Label } & \multicolumn{2}{|c|}{ Share/average in households } \\
\hline & & $\begin{array}{l}\text { With disabled } \\
\text { member(s) }\end{array}$ & $\begin{array}{l}\text { Without disabled } \\
\text { member(s) }\end{array}$ \\
\hline \multicolumn{4}{|c|}{ Dependent variable: class of work intensity (WI): Work intensity } \\
\hline$W I=0$ & & $35.8 \%$ & $25.7 \%$ \\
\hline $0<W I<0.5$ & & $3.2 \%$ & $2.7 \%$ \\
\hline $0.5 \leq W I<1$ & & $12.0 \%$ & $12.3 \%$ \\
\hline$W I=1$ & & $49.0 \%$ & $59.3 \%$ \\
\hline \multicolumn{4}{|l|}{ Independent variables: } \\
\hline Age between 18 and 24 years & Age $18-24$ & $5.9 \%$ & $4.6 \%$ \\
\hline Age between 25 and 34 years & Age $25-34$ & $18.9 \%$ & $19.7 \%$ \\
\hline Age between 35 and 44 years & Age $35-44$ & $20.4 \%$ & $29.4 \%$ \\
\hline Age between 45 and 54 years & Age $45-54$ & $34.9 \%$ & $32.6 \%$ \\
\hline Age between 55 and 59 years & Age $55-59$ & $19.9 \%$ & $13.7 \%$ \\
\hline \multirow[t]{4}{*}{ Education level } & Edulevel & & \\
\hline & Primary & $37.1 \%$ & $28.7 \%$ \\
\hline & Secondary & $46.2 \%$ & $49.7 \%$ \\
\hline & Tertiary & $16.7 \%$ & $21.6 \%$ \\
\hline Being female & Female & $50.9 \%$ & $50.1 \%$ \\
\hline Having children between 0 and 15 years & Kids & $25.7 \%$ & $37.8 \%$ \\
\hline Being immigrant & Immigrant & $8.8 \%$ & $12.4 \%$ \\
\hline Having the other members income ${ }^{*}$ & Other members & $29.4 \%$ & $33.5 \%$ \\
\hline in the first quartile of its distribution & Income 1q & & \\
\hline Having the other members income* & Other members & $26.6 \%$ & $27.6 \%$ \\
\hline
\end{tabular}


Table A1 continued

\begin{tabular}{|c|c|c|c|}
\hline \multirow[t]{2}{*}{ Variable } & \multirow[t]{2}{*}{ Label } & \multicolumn{2}{|c|}{ Share/average in households } \\
\hline & & $\begin{array}{l}\text { With disabled } \\
\text { member(s) }\end{array}$ & $\begin{array}{l}\text { Without disabled } \\
\text { member(s) }\end{array}$ \\
\hline in the second quartile of its distribution & Income $2 q$ & & \\
\hline $\begin{array}{l}\text { Having theother members income } \\
\text { in the third quartile of its distribution }\end{array}$ & $\begin{array}{l}\text { Other members } \\
\text { Income } 3 q\end{array}$ & $23.8 \%$ & $22.9 \%$ \\
\hline $\begin{array}{l}\text { Having the other members income } \\
\text { in the fourth quartile of its distribution }\end{array}$ & $\begin{array}{l}\text { Other members } \\
\text { Income } 4 \mathrm{q}\end{array}$ & $20.2 \%$ & $16.0 \%$ \\
\hline Being disabled person with severe limitations & $\begin{array}{l}\text { Own strong } \\
\text { Disability }\end{array}$ & $8.7 \%$ & \\
\hline Being disabled person with mild limitations & $\begin{array}{l}\text { Own mild } \\
\text { Disability }\end{array}$ & $36.0 \%$ & \\
\hline $\begin{array}{l}\text { Having in the household at least one } \\
\text { disabled member with severe limitations }\end{array}$ & $\begin{array}{l}\text { Presence of severe } \\
\text { Disabled }\end{array}$ & $26.6 \%$ & \\
\hline Number of individuals in the household & $N$ components & 3.3 & 3.0 \\
\hline $\begin{array}{l}\text { Having in the household at least one old } \\
\text { person (age }<65 \text { ) with no disability }\end{array}$ & Elderly nd & $8.4 \%$ & $8.0 \%$ \\
\hline \multirow[t]{4}{*}{ Regions of the household } & Region & & \\
\hline & North & $45.4 \%$ & $50.9 \%$ \\
\hline & Center & $25.2 \%$ & $23.7 \%$ \\
\hline & South & $29.4 \%$ & $25.4 \%$ \\
\hline Living in an Urbanized area & Urban & $38.4 \%$ & $30.5 \%$ \\
\hline Being owner of the house & Owner & $40.9 \%$ & $50.0 \%$ \\
\hline Being employed in the public sector & Public employee & $6.2 \%$ & $8.1 \%$ \\
\hline Being parent of a disabled person & Parent & $7.0 \%$ & \\
\hline Being son or daughter of a disabled person & Son/daughter & $33.3 \%$ & \\
\hline Being partner of a disabled person & Partner & $27.3 \%$ & \\
\hline
\end{tabular}

*The Other Members Income is calculated as the income (in thousand Euros) of the family excluding the income of the individual 
Table A2 Ordered logit model odds ratios estimated for the sample of households without children age $0-15$

Dependent variable: Class of Work Intensity

(1)

With Disabled

member(s)

Age - reference: age 35-44

Age 18-24

Age 25-34

Age 45-54

Age 55-59

Edulevel - reference: primary

Edulevel (Secondary)

Edulevel (Tertiary)

Female

Immigrant

Other members income - reference: $3 q$

Other members income $1 \mathrm{q}$

Other members income $2 q$

Other members income $4 \mathrm{q}$

Own strong disability

Own mild disability

Presence of severe disabled

$N$ components

Elderly nd

Region - reference: center

$$
\begin{aligned}
& \text { Region (north) } \\
& \text { Region (south) }
\end{aligned}
$$

Urban

Owner

Public employee

Parent

Son/daughter

Partner

Female* presence of severe disabled

Observations

AIC

${ }^{*} p<0.1 ;{ }^{* *} p<0.05 ;{ }^{* * *} p<0.01$

$1.473^{* * *}$

$1.230^{* *}$

0.946

$0.427^{* * *}$

1.016

$0.553^{* * *}$

0.891

$1.380^{* * *}$

$0.502^{* * *}$

$1.144^{* * *}$

1.048

$3.082^{* * *}$

$1.517^{* * *}$

1.003

$1.279^{* * *}$

$1.882^{* * *}$

4487

8774.66
(2)

Without Disabled member(s)

$\begin{array}{ll}0.260^{* * *} & 0.195^{* * *} \\ 0.481^{* * *} & 0.424^{* * *} \\ 1.064 & 1.155^{* *} \\ 0.897 & 0.984\end{array}$

$\begin{array}{ll}2.230^{* * *} & 2.144^{* * *} \\ 2.673^{* * *} & 2.816^{* * *} \\ 0.336^{* * *} & 0.359^{* * *} \\ 0.830^{*} & 0.738^{* * *}\end{array}$

$1.440^{* * * *}$

1.042

$0.820^{* * * *}$

$1.058 \quad 0.885^{* * *}$

$0.657^{* * *}$

$1.199^{* * *}$

$0.493^{* * *}$

$1.117^{* * *}$

$1.211^{* * *}$

$2.240^{* * * *}$

10996

19858.29 
Table A3 Ordered logit model odds ratios estimated for the sample of households with disabled member(s) with and without disability benefits in the covariates

Dependent variable: Class of Work Intensity

(1)

(2)

Without Disability Bf

With Disability Bf

Age - reference: age 35-44

Age 18-24

Age 25-34

Age 45-54

Age 55-59

Edulevel - reference: primary

Edulevel (Secondary)

Edulevel (Tertiary)

Female

Kids

Female*kids

Immigrant

Other members income - reference: $3 q$

Other members income $1 \mathrm{q}$

Other members income $2 \mathrm{q}$

Other members income $4 \mathrm{q}$

Own strong disability

Own mild disability

Presence of severe disabled

To receive disability benefits

$\mathrm{N}$ components

Elderly nd

Region - reference: center

Region (north)

Region (south)

Urban

Owner

Public employee

Parent

Son/daughter

Partner

Female* presence of severe disabled

Observations

AIC

${ }^{*} p<0.1 ;{ }^{* *} p<0.05 ;{ }^{* * *} p<0.01$

$\begin{array}{ll}0.252^{* * *} & 0.240^{* * *} \\ 0.504^{* * *} & 0.488^{* * *} \\ 1.135^{*} & 1.170^{* *} \\ 0.929 & 0.980\end{array}$

$2.169^{* * *}$

$2.039^{* * *}$

$2.943^{* * *}$

$2.681^{* * *}$

$0.346^{* * *}$

$0.334^{* * *}$

$1.729^{* * *}$

$1.704^{* * *}$

$0.527^{* * *}$

$0.518^{* * *}$

$0.724^{\text {*** }}$

$0.713^{* * *}$

$1.412^{* * *}$

$1.280^{* * *}$

$1.309^{\text {*** }}$

$1.248^{* * * *}$

1.064

1.064

$0.494^{* * *}$

$0.821^{*}$

0.949

0.981

$0.623^{\text {*** }}$

$0.631^{* * *}$

$0.191^{* * * *}$

1.014

0.997

0.892

0.913

$1.377^{* * *}$

$1.340^{* * *}$

$0.503^{\text {*** }}$

$0.504^{* * *}$

$1.132^{* * *}$

$1.135^{\text {*** }}$

1.007

1.019

$2.899^{* * *}$

$2.884^{* *}$

$1.332^{* *}$

$1.269^{* *}$

0.962

0.949

$1.190^{* *}$

1.111

$1.635^{\text {*** }}$

$1.529^{* * *}$

6039

6039

11728.15
11556.41 


\section{References}

Agovino, M., Parodi, G. and Sciulli, D. (2014). The dynamics of disability and labour force participation in Italy, Disadvantaged Workers, Springer (pp. 31-48).

Antecol, H. (2000). An examination of cross-country differences in the gender gap in labor force participation rates. Labour Economics, 7(4), 409-426.

Atkinson, A., Finney, A. and McKay, S. (2007). Health, disability, caring and employment: longitudinal analysis, Research Report No 461.

Ayllón, S., \& Gábos, A. (2017). The interrelationships between the Europe 2020 poverty and social exclusion indicators. Social Indicators Research, 130(3), 1025-1049.

Bernardi, F., Garrido, L., \& Miyar, M. (2011). The recent fast upsurge of immigrants in Spain and their employment patterns and occupational attainment. International Migration, 49(1), 148-187.

Bettio, F., \& Plantenga, J. (2004). Comparing care regimes in Europe. Feminist Economics, 10(1), 85-113.

Bettio, F., Simonazzi, A., \& Villa, P. (2006). Change in care regimes and female migration: the 'care drain' in the Mediterranean. Journal of European Social Policy, 16(3), 271-285.

Bound, J., \& Burkhauser, R. V. (1999). Economic analysis of transfer programs targeted on people with disabilities. Handbook of Labor Economics, 3, 3417-3528.

Brandolini, A., \& Viviano, E. (2016). Behind and beyond the (head count) employment rate. Journal of the Royal Statistical Society: Series A (Statistics in Society), 179(3), 657-681.

Burkhauser, R. V., Daly, M. C., Houtenville, A. J. \& Nargis, N. (2001). The employment of working-age people with disabilities in the 1980s and 1990s: what current data can and cannot tell us, FRB of San Francisco Working Paper No. 2001-20, 1-41.

Burkhauser, R. V., Daly, M. C., McVicar, D., \& Wilkins, R. (2014). Disability benefit growth and disability reform in the us: lessons from other OECD nations. IZA Journal of Labor Policy, 3(1), 4.

Cai, L. (2010). The relationship between health and labour force participation: evidence from a panel data simultaneous equation model. Labour Economics, 17(1), 77-90.

Cohen, J., Cohen, P., West, S. G. \& Aiken, L. S. (2003). Applied Multiple Regression/Correlation Analysis for the Behavioral Sciences, (3rd ed. pp. 46-47), Mahwah, New Jersey: Lawrence Erlbaum Associates, Publishers

Contoyannis, P., Jones, A. M., \& Rice, N. (2004). The dynamics of health in the british household panel survey. Journal of Applied Econometrics, 19(4), 473-503.

Cordini, M., \& Ranci, C. (2017). Legitimising the care market: the social recognition of migrant care workers in Italy. Journal of Social Policy, 46(1), 91-108.

Cullinan, J., Gannon, B., \& Lyons, S. (2011). Estimating the extra cost of living for people with disabilities. Health Economics, 20(5), 582-599.

Da Roit, B., Gonzalez Ferrer, A., \& Moreno-Fuentes, F. J. (2013). The southern European migrant-based care model: long-term care and employment trajectories in Italy and Spain. European Societies, 15 (4), 577-596.

Da Roit, B., \& Sabatinelli, S. (2013). Nothing on the move or just going private? understanding the freeze on child-and eldercare policies and the development of care markets in Italy. Social Politics, 20(3), 430-453.

Eichhorst, W., et al. (2010). The mobility and integration of people with disabilities into the labour market, WIFO Studies, WIFO, 42370.

European Commission (2010). Europe 2020, a European Strategy for Smart, Sustainable and Inclusive Growth, European Commission, Brussels (Communication from the Commission, COM (2010) 2020).

European Commission (2014). Taking Stock of the Europe 2020 Strategy for Smart, Sustainable and Inclusive Growth., European Commission, Brussels (Communication from the Commission, COM (2014) 130 final).

Gannon, B. (2005). A dynamic analysis of disability and labour force participation in Ireland 1995-2000. Health Economics, 14(9), 925-938.

García-Gómez, P., Jones, A. M., \& Rice, N. (2010). Health effects on labour market exits and entries. Labour Economics, 17(1), 62-76.

Greene, W. H. (2003). Econometric Analysis, Pearson Education India.

ILO (2019). World employment social outlook, technical report, International Labour Organization.

Kidd, M. P., Sloane, P. J., \& Ferko, I. (2000). Disability and the labour market: an analysis of British males. Journal of Health Economics, 19(6), 961-981. 
Le Bihan, B., Da Roit, B., \& Sopadzhiyan, A. (2019). The turn to optional familialism through the market: long-term care, cash-for-care, and caregiving policies in europe. Social Policy \& Administration, 53(4), 579-595.

Lilly, M. B., Laporte, A., \& Coyte, P. C. (2010). Do they care too much to work? the influence of caregiving intensity on the labour force participation of unpaid caregivers in Canada. Journal of Health Economics, 29(6), 895-903.

Luppi, M., \& Nazio, T. (2019). Does gender top family ties? within-couple and between-sibling sharing of elderly care. European Sociological Review, 35(6), 772-789.

Meulders, D., et al. (2013). The working poor: too low wage or too many kids? American International Journal of Contemporary Research, 3(7), 30-46.

Mitra, S., Palmer, M., Kim, H., Mont, D., \& Groce, N. (2017). Extra costs of living with a disability: a review and agenda for research. Disability and Health Journal, 10(4), 475-484.

Morciano, M., Hancock, R., \& Pudney, S. (2015). Disability costs and equivalence scales in the older population in great Britain. Review of Income and Wealth, 61(3), 494-514.

Morris, Z. A., \& Zaidi, A. (2020). Estimating the extra costs of disability in european countries: implications for poverty measurement and disability-related decommodification. Journal of European Social Policy, 30(3), 339-354.

Murray, C., Tandon, A., Salomon, J. and Mathers, C. (2001). Enhancing cross-ppopulation comparability of survey results, World Health Organisation, GPE Discussion Paper (35).

Mussida, C., \& Sciulli, D. (2016). Disability and employment across Central and Eastern European countries. IZA Journal of Labor \& Development, 5(1), 4.

Nys, A., Meeusen, L., \& Corluy, V. (2016). Who cares? a counterfactual analysis of household work intensity in households with disabled family members. Social Indicators Research, 128(2), 675-691.

Oguzoglu, U. (2010). Dynamics of work limitation and work in Australia. Health Economics, 19(6), 656-669.

Parodi, G., \& Sciulli, D. (2008). Disability in italian households: income, poverty and labour market participation. Applied Economics, 40(20), 2615-2630.

Ranci, C., Da Roit, B. and Pavolini, E. (2008). Tutelare la Non Autosufficienza, Carocci: Rome. Pg. 40-83.

Ranci Ortigosa, C., Da Roit, B. and Emmanuele, P. (2008). Partire dall'Esistente: Le Caratteristiche dell'Indennità di Accompagnamento e Alcune Proposte di Riforma.

Sadana, R., Mathers, C. D., Lopez, A. D., Murray, C. J. and Iburg, K. (2002). Comparative analyses of more than 50 household surveys on health status, Summary measures of population health: concepts, ethics, measurement and applications pp. 369-386.

Schneider, U., Trukeschitz, B., Mühlmann, R., \& Ponocny, I. (2013). "Do I Stay or Do I Go?"- job change and labor market exit intentions of employees providing informal care to older adults. Health Economics, 22(10), 1230-1249.

Simonazzi, A. (2009). Care regimes and national employment models. Cambridge Journal of Economics, 33(2), 211-232.

Stern, S. (1989). Measuring the Effect of Disability on Labor Force Participation, Journal of human Resources pp. 361-395.

Theobald, H., \& Luppi, M. (2018). Elderly care in changing societies: concurrences in divergent care regimes - a comparison of Germany, Sweden and Italy. Current Sociology, 66(4), 629-642.

United Nations (2018). United Nations 2018 flagship report on disability and development: realization of the sustainable development goals by, for and with persons with disabilities, un doc, Technical report, $\mathrm{A} / 73 / 220$.

United Nations (2019). The sustainable development goals report 2019, Technical report, United Nation.

Vinck, J. \& Van Lancker, W. (2020). An intersectional approach towards parental employment in families with a child with a disability: the case of Belgium, Work, Employment and Society, 34(2), 228-261.

Wasi, N., van den Berg, B., \& Buchmueller, T. C. (2012). Heterogeneous effects of child disability on maternal labor supply: evidence from the 2000 US census. Labour Economics, 19(1), 139-154.

Zanobini, M., Viterbori, P., Garello, V. \& Camba, R. (2018). Parental satisfaction with disabled children's school inclusion in Italy. European Journal of Special Needs Education, 33(5), 597-614. 